\title{
Occupational therapy home programmes for children with cerebral palsy: A national survey of United Kingdom paediatric occupational therapy practice
}

Short title: Survey of home programmes for children with cerebral palsy

\section{Author List:}

1.Yvonne M Milton, Senior Occupational Therapy Lecturer, Faculty of Health and Life

Sciences, Coventry University, UK; Occupational Therapist, Adoptionplus, Buckinghamshire, UK.

2.Carolyn Dunford, Senior Occupational Therapy Lecturer, Department of Clinical Sciences Brunel University, UK

3.Katie V Newby, Senior Research Fellow, Centre for Advances in Behavioural Science, Coventry University, UK

\section{Corresponding author}

Yvonne M Milton, Faculty of Health and Life Sciences, Coventry University, Coventry, Priory Street, CV1 5FB. Email: Yvonne.milton@,coventry.ac.uk 


\section{Abstract}

Introduction: Occupational therapy home programmes for children with cerebral palsy have a robust evidence base but their content and usage in United Kingdom practice is unknown. Method: A national online survey questionnaire was conducted with occupational therapists to explore their current occupational therapy home programme (OTHP) practices, and attitudes toward using OTHPs with children with cerebral palsy. Recruitment was through members of two sections of the Royal College of Occupational Therapists; a University's Fieldwork-Supervisor's Database and self-selection following promotion on occupational therapy networks, social media and newsletters.

Results: Of all survey respondents $(n=123)$, the majority of respondents $(n=74 ; 60 \%$;) used OTHPs. The uptake and use of evidence-based OTHP content varied, revealing evidencepractice gaps. Respondents clearly articulated their professional reasoning and acknowledged benefits of using OTHPs. However, they reported barriers to implementing them within a Family-Centred framework citing time constraints, lack of knowledge, skills and training plus insufficient support.

Conclusion: Occupational therapists report challenges to implementing evidence-based interventions and routine, systematic application of a range of standardised measurement tools pre/post OTHP. This would enhance quality outcomes for children with cerebral palsy and their families. However, occupational therapists indicated the need for greater organisational support, further education and skill development in these areas.

\section{Keywords}

Home programmes, cerebral palsy, survey 


\section{Introduction}

Cerebral palsy (CP) is a common disability in children and young people. The prevalence of $\mathrm{CP}$ is 2.11 per 1000 live births (Oskoui et al., 2013). Occupational therapy home programmes (OTHPs) for children with cerebral palsy (CWCP) have been used for some time now by families and therapists to increase the intensity of therapy, either between therapy sessions or during a break from therapy (Novak and Cusick, 2006). OTHPs have been defined as a method of service delivery, 'that target body structure, activities, and participation problems identified collaboratively by the parents and therapist' (Novak et al., 2009: 607). OTHPs for CWCP, aim to induce neuroplasticity and improve motor activity performance and/or selfcare function, through regular practice and participation in meaningful, occupation-based activities (Novak et al., 2013). OTHPs are carried out by parents at home, becoming "a part of life" rather than an additional responsibility (Novak, 2011: 203). OTHPs form an essential part of child-active rehabilitation services (Novak and Berry, 2014), and complement and intensify the effects of sessions delivered by occupational therapists (Novak et al., 2009).

Occupational therapists are obliged to deliver interventions that sustain resources and are cost-effective, efficient and based upon both best practice and the most recent evidence available (College of Occupational Therapists [COT], 2015). OTHP quality outcomes depend on "what" is done and "how" it is done (Novak and Berry, 2014: 385). However current OTHP delivery, and whether it is congruent with best practice and evidence, is unexplored. In this study OTHP content was grouped as: (a) Approaches $=$ theories, conceptual models of practice and frameworks; (b) Interventions = methods and specific activities; and (c) Measures $=$ assessments, outcome measures, goal-setting and classification tools. In order to explore whether CWCP receive the best, high quality care available, an understanding of occupational therapists' current use of evidence-based OTHPs is valuable. This paper outlines 
the results of a national study investigating the usage, content and professional reasoning process supporting OTHPs for CWCP in the United Kingdom (UK).

\section{Literature review}

\section{Home programme content: best practice and evidence}

Evidence-based practice (EBP) is an essential standard of proficiency for occupational therapists (Health and Care Professions Council, 2013). EBP and reflective practice are important components of professional reasoning which occupational therapists use throughout the therapy process. Using evidence-based OTHPs entails a degree of complexity which requires a reciprocal relationship between the parents, child and therapist, working in combination within the home context using individual support methods (Milton and Roe, 2017). The approaches, interventions and measures chosen will vary, although it is vital that those selected deliver quality OTHP outcomes. Approaches include family-centred care (FCC) (Rosenbaum et al., 1998), motor learning-based and cognitive approaches. Interventions include collaborative goal-setting; construction of the OTHP in the home context (Novak and Berry, 2014) with interventions organised around every-day routines (McConnell et al., 2015); action observation therapy (Kirkpatrick et al., 2016); cognitive orientation to daily occupational performance (CO-OP) (Cameron et al., 2017); regular parental support, information, education and coaching (Aitkin et al., 2005; Novak \& Cusick, 2006); and logbooks to record parent training (Novak et al., 2009). Bimanual training (BT) and modified constraint induced movement therapy or constraint induced movement therapy 
(m-CIMT/CIMT) are interventions that are adapted by occupational therapists for use in OTHPs (Sakzewski et al., 2013; National Institute for Health \& Clinical Excellence [NICE], 2012).

An essential part of occupational therapy is the incorporation of valid outcome measurement in the occupational therapy process to document outcomes and demonstrate the efficacy of occupational therapy interventions (Unsworth, 2001). Following the publication of the Department of Health's 'Equity and excellence: liberating the NHS' in 2010, there has been the requirement for clinicians to use evidence-based measures, and to demonstrate improving health outcomes. Within the OTHP literature, measures such as the Assisting Hand Assessment (Krumlinde-Sundolm et al., 2007); Goal Attainment Scaling (GAS) (Kiresuk and Sherman, 1968); and the Canadian Occupational Performance Measure (Law et al., 2014) have been used to evaluate OTHP outcomes (Novak et al., 2009). Furthermore, measurement tools such as the Gross Motor Classification System (GMFCS) and Manual Classification System (MACS) (Carnahan et al., 2007) have been used to determine levels of function in CWCP.

\section{Paediatric occupational therapy practice with children with cerebral palsy}

In regard to the evidence-based approaches, interventions and measures paediatric occupational therapists use, other than OTHPs specifically, four studies were identified (Rodger, Brown \& Brown, 2005; Saleh et al, 2008, McConnell et al., 2012; Sakzewski et al., 2013). The first study (Rodger et al., 2005) found that the assessment and treatment methods most frequently used for developmental delay, learning disability, neurology and infants/toddlers client groups, were not congruent with the most commonly used theoretical 
models. The same study concluded that occupational therapists need to examine the evidence and determine whether their clinical practice is grounded in the best contemporary theoretical models, assessments and interventions. The second study investigated occupational and physiotherapy practices for young CWCP and found large variations in practice, and gaps in the incorporation of evidence-based best practices into clinical practice (Saleh et al., 2008). It was concluded that the evidence gaps were unlikely to be attributable exclusively to limited time or resources but also to the slow uptake of EBP in daily clinical practice. The third study by McConnell et al (2012) examined the therapy management of the upper limb in CWCP and found that therapists frequently reported using positioning, neurodevelopmental therapy (NDT) and task practice to treat upper limb dysfunction. It was concluded that CWCP's upper limb management could be improved with the use of evidence-based interventions. The fourth study investigated the barriers and enablers to delivering evidence-based upper-limb rehabilitation for CWCP and found that therapists were confident in delivering BT but less knowledgeable and skilled, and hence confident, in providing CIMT (Sakzewski et al., 2013).

\section{OTHPs for children with cerebral palsy}

In order that an OTHP will work, therapists need to know how to apply and translate the best available evidence into efficient and effective practice. However, with the need for greater specification of OTHP content in the literature, this could be challenging for therapists (Milton and Roe, 2017). It is unknown whether or not occupational therapists' usage and content of OTHPs for CWCP, is congruent with best practice and evidence. Furthermore, despite assurances of OTHP and intervention efficacy (Novak et al., 2013, p. 899), clinicians have indicated a need for training and skill development in their use (Sakzweski et al., 2013). To provide support for occupational therapists choosing to use OTHPs for CWCP, the first 
step is to understand current practice. Hence we sought to answer the research question; "what is the usage, content and professional reasoning process supporting OTHPs for CWCP?".

\section{Method}

\section{Participants and Procedure}

The study used a cross-sectional survey design in order to capture information regarding the usage, content and professional reasoning process supporting OTHPs for CWCP. Coventry University Ethics Committee approval was obtained prior to commencement of the study. Recruitment was through direct invitation and self-selection following promotion via occupational therapy networks/social media. Following permission from relevant gatekeepers, surveys were emailed directly to members of the 'Royal College of Occupational Therapists' 'Independent Practice,' 'Children and Young People and Families' specialist sections, (IP-SS; CYPF-SS) and the 'Practice Educator's Database'. Secondly, the survey was promoted online via the CYPF-SS website in addition to notifications at national RCOT and CYPF-SS training events. The autonomy of the participants was assured through informed consent which was sought through the inclusion of a consent page within the online survey. The inclusion criteria for this study were (i) consenting to participate; (ii) being an occupational therapist in the UK; and (iii) using OTHPs for CWCP. 


\section{Instrument}

Data for the study was gathered using an adapted version of a survey previously used to describe occupational therapy practices in the usage, prescription of and clinical reasoning process supporting home exercise programmes for clients with neurological injuries in the USA (Proffitt, 2016). Following permission, the survey by Proffitt (2016) was adapted to meet this study's purpose and population. It was piloted with experienced occupational therapists in the UK $(n=5)$ to determine face and content validity. Recommended changes were made to this adapted final version before it was distributed electronically. The full survey is detailed in the Appendix. The occupational therapists who piloted the survey were not associated with the development of the questionnaire and were excluded from the survey responses. There were 16 survey questions in total. Four questions related to demographics: whether or not respondents used OTHPs, provision to different classifications of CP, years of experience and employer. Four open-ended questions were related to OTHP frequency; instruction of when OTHPs should be used; suggestions for how OTHPs could be made easier to use; and suggestions about the type and content of professional development/educational solutions that would improve the design and use of OTHPs for CWCP. Four questions were Likert-scale questions designed to ascertain occupational therapists' opinions on the use and value of OTHPs for CWCP and goal-setting practices One question related to barriers that have an impact on the use of OTHPs. Two open-ended questions asked occupational therapists about the professional reasoning underlying the selection of OTHPs for CWCP. 


\section{Data analysis}

The responses were exported into a SPSS file (IBM SPSS Statistics Version 24) and screened for errors and omissions to ensure data integrity. Nominal and ordinal data was analysed using descriptive statistics and frequencies. Post hoc correlations were calculated to identify potential relationships between survey respondent demographics and questionnaire responses. Likert-scale question categories 'usually and often' were collapsed to form 'frequently' for purposes of analysis. The open-ended question about OTHP dosage was coded separately by the author and one other researcher. The answers were then grouped into categories for descriptive analysis. The other open-ended questions were coded by the same two researchers and themes were identified from the data. Occupational therapists who indicated that they did not use OTHPs were grouped and their data were analysed separately using the same methods.

\section{Results}

There were 123 surveys returned. Of this total 49 (40\%) reported that they did not use OTHPs because: they were working in an academic setting (4), they did not work regularly with children with CP (17), OTHPs were not the main focus or remit within their service of their work ( $\mathrm{n}=14)$, time constraints $(\mathrm{n}=9)$, lack of support $(\mathrm{n}=1)$, lack of knowledge of specific methods ( $n=3)$, and poor evidence parents follow home programmes $(n=1)$. The subsequent analysis is based on the proportion of occupational therapists who used OTHPs ( $\mathrm{n}=74 ; 60 \%)$. 


\section{Demographics}

The respondents' amount of clinical experience varied. Eighteen (24.3\%) had six to 10 years, $13(17.6 \%)$ had up to five years and nine $(12.2 \%)$ had 11 to 15 years. The majority of respondents had over 15 year's experience $(n=34 ; 45.9 \%)$. The number of respondents in each employment category were: National Health Service (NHS, state employer) $(\mathrm{n}=50 ; 67.5 \%)$; self-employed $(\mathrm{n}=10 ; 13.5 \%)$; charity $(\mathrm{n}=5 ; 6.8 \%)$; private $(\mathrm{n}=4 ; 5.4 \%)$; NHS and selfemployed $(\mathrm{n}=3 ; 4.0 \%)$; health service, Ireland $(\mathrm{n}=1 ; 1.4 \%)$; social services $(\mathrm{n}=1 ; 1.4 \%)$. The respondents were asked which classification(s) of CWCP they provided OTHPs for, with the option of selecting more than one category: children with hemiplegia were the largest group $(\mathrm{n}=69 ; 93.2 \%)$; followed by children with quadriplegia $(\mathrm{n}=62 ; 89.9 \%)$; diplegia $(\mathrm{n}=58$; 93.5\%) or other classification ( $\mathrm{n}=17 ; 70.8 \%)$. No statistically significant correlations were found between respondent demographics and use of approaches, intervention or measures.

\section{Home Programme Usage and Content}

\section{Approaches: theories, conceptual models of practice and frameworks}

A FCC framework/approach and conceptual models of practice were reported to be used frequently by the majority of respondents (Figure 1). The majority of respondents agreed that there were barriers to using OTHPs $(\mathrm{n}=67 ; 90.5 \%)$. Due to the barriers, using OTHPs within a FCC framework/approach was reported to be challenging. The most frequently cited barriers 
were insufficient time $(n=60)$; insufficient support $(n=27)$; lack of knowledge of specific methods $(n=24)$; lack of confidence $(n=23)$; lack of training $(n=19)$, and a lack of skills $(n=$ $18)$.

Figure 1. Approaches, theories, conceptual models of practice and frameworks used by respondents

\section{Interventions: methods and specific activities}

The types of interventions and how often they were used varied (Figure 1). The interventions used most frequently, each selected by more than $62 \%(n=46)$ respondents, were activities of daily living (ADL), activity analysis, fine motor activities, and active range of motion. The majority of respondents did not use coaching frequently $(n=38 ; 55.8 \%)$. The CO-OP, CIMT/m-CIMT were rarely used. NDT/Bobath therapy and sensory integration interventions, "not recommended for standard care" (Novak et al., 2013 p900), were used often by some therapists (Figure 1). Methods used to educate parents about an OTHP included demonstration and explanation of activities $(n=69 ; 93.2 \%)$; modelling and grading activities $(\mathrm{n}=58 ; 79.5 \%)$; providing hand-outs with text/photographs $(\mathrm{n}=35 ; 47.3 \%)$ and videos for later review $(\mathrm{n}=10 ; 13.7 \%)$. There was unanimous agreement that parents should be involved in the design of OTHPs. However respondents described the provision of support/ training with 
parents as unsatisfactory $(n=38 ; 55 \%)$. Logbooks to measure how much practice parents did were rarely used.

\section{Measures used}

Respondents rarely used evidence-based fine motor measures or classification tools to determine a child's current level of function. Likewise, recommended goal-setting measures such as the Canadian Occupational Performance Measure (COPM) or Perceived Efficacy Goal-Setting (PEGS) (Pollock and Missiuna, 2015), to assess children or family goals, were rarely used (Figure 2). Whilst acknowledging that some measures can be used for multiple purposes, informal rather than standardised goal-setting methods were used to measure outcomes (Figure 2). Respondents used environmental assessments the most and uni-manual assessments the least (Figure 2). Specific environmental assessments were not identified.

\section{Figure 2. Type and use of Measures used by respondents}

\section{Measures Applied: When and How}

OTHP measurement was not comprehensive or consistent with a FCC approach. Although the majority of respondents frequently set goals in collaboration with parents pre-OTHP $(n=48$; $64.9 \%)$, respondents measured goals less frequently after carrying out the OTHP $(n=42 ; 56.8$ \%). Similarly not all respondents evaluated outcomes with the family $(n=24 ; 32.4 \%)$.

Children $(n=50 ; 67.6 \%)$ were less involved in goal-setting than parents $(n=66 ; 89.2 \%)$. In 
open-ended responses a majority of respondents reported that there was room for improvement with their OTHP goal-setting practice. The majority of respondents reported that if parents did not have a clear goal themselves, therapists would often determine the goals, as they did not have the time or skills to facilitate parents to set goals themselves.

\section{OTHP implementation: When and duration}

The dosage (quantity of time) respondents advised parents to carry out OTHPs varied; every day $(\mathrm{N}=37 ; 54 \%)$ was the most frequent dosage, followed by $2-3$ times a week $(n=17 ; 25 \%)$; once a week $(n=9 ; 13.2 \%)$ or other amount $(n=5 ; 7.3 \%)$. Due to the large variation in response it was not possible to determine an exact OTHP dosage in terms of hours/minutes per day/week, or length of overall time parents carried out an OTHP before it is reviewed. The majority of respondents reported that they advised parents to carry out OTHPs on a daily basis, although a consensus on a precise dosage was not reached. The majority of respondents reported that they would advise parents to carry out the programme whenever it fitted into their routine best.

\section{Professional reasoning and development}

The respondents reported several factors that guided their professional reasoning to decide what to use and how to implement it. The majority of respondents agreed that the families' goals were a primary factor in deciding which content to use. As expected, the child and family's capabilities and available supports guided the choice of activities and the dosage and progression of an OTHP over time. The child's chronological age or cognitive ability guided 
whether or not they were included in the goal-setting process. Only two respondents referred to the evidence influencing OTHP development or professional reasoning, and none cited specific studies.

The main themes that arose from qualitative analysis regarding the type and content of professional development/educational solutions to improve OTHPs were training in programme implementation; evidence-based interventions; goal-setting; coaching techniques; CO-OP; outcome measures and evidence of their efficacy. Two themes emerged from qualitative analysis regarding how OTHPs could be made easier to use. Theme one was factors relating to the environment; as expected therapists reported OTHPs would be easier with more time and resources. Theme two, technological factors included a) more frequent use of videos for parent training, digital platforms and online technology and b) the development of computer programmes written specifically for occupational therapists.

\section{Perceived benefits of OTHPs}

The majority of respondents $(n=74 ; 60 \%)$ used OTHPs. A majority of respondents agreed "consistency of therapeutic approach is important," (n=36; 48.6\%) and that OTHPs "help children meet the goals that cannot be met with the limited one-to-one therapy allotted" $(\mathrm{n}=38 ; 51.4 \%)$. The statements agreed by the majority of respondents were "OTHPs allow for greater participation in the child's natural home environment" ( $\mathrm{n}=49 ; 66.2 \%)$; chosen OTHP activities "should be functional and embedded into the child's routine" ( $\mathrm{n}=70 ; 94.6 \%)$; and "OTHPs reinforce carryover of therapy activities into the child's environment $(n=54 ; 73 \%)$."

The majority of respondents gave a neutral response to the statements "OTHPs are effective" ( $\mathrm{n}=67 ; 90.5 \%)$, and "I am confident designing OTHPs" ( $\mathrm{n}=56 ; 75.7 \%)$.

Consequently, whether OTHPs are perceived to be effective, or whether occupational 
therapists have confidence designing them, remains uncertain. Finally, the majority of respondents agreed that OTHPs could be designed in the home or school environment $(\mathrm{n}=56$; 77.8\%); the home context was not deemed an essential place to design OTHPs.

\section{Discussion}

The findings of this study contribute to the limited body of knowledge available about OTHP practice for CWCP. It is the first published national survey among UK-based occupational therapists to identify the current usage, content and professional reasoning supporting OTHPs for CWCP. Analysis of the survey resulted in three key areas for discussion. First, the use of a FCC framework by most occupational therapists, was not congruent with their statements regarding OTHP design location, or method of measuring outcomes. Secondly, the uptake and application of evidence-based interventions was varied and inconsistent. Thirdly, despite the robust evidence-base, occupational therapists were undecided whether or not OTHPs are effective. This correlates with the lack of uptake and use of measures to a) determine the child's current level of function; b) measure family/children's goals; and c) objectively measure post-OTHP outcomes.

\section{Family-Centred Care Framework}

OTHP design location. The majority of occupational therapists did not consider the home context to be an essential place to construct OTHPs with parents. The design of an OTHP in a child's home forms an important part of successful home programme implementation in the evidence-based practice literature (Novak and Cusick, 2006; Kirkpatrick et al., 2016). Parents prefer to work activities out in collaboration with the therapist at home so the activities are 
more individualised and easy to duplicate into occupation-based daily activities (Novak et al., 2009; Novak, 2011). Furthermore when therapists find ways to utilize natural routines as a means to support children's goal attainment, their practice represents the essence of occupational therapy (Rodger and Ziviani, 2006). Designing OTHPs in the home context, rather than relying on verbal reports from families to understand the complicated environmental influences on occupational performance, not only enables a greater understanding of parental concerns, but also tends to lead to more realistic goals and solutions (Novak and Cusick, 2006). Being able to see first-hand the functional abilities of the child in this environment helps the therapist understand how best to incorporate therapy activities that will be meaningful, achievable and enjoyable for the child and family (Rodger and Ziviani, 2006). Similarly, when therapists identify ways to support children in the home context, they ultimately provide more opportunities for skills practice, thus meeting a primary intent of service provision (Hanft and Pilkington, 2000). However, despite the evidence of the positive influence on occupational performance, the home is often overlooked as a focus for structuring and modelling intervention because of the cost of home visits by a therapist (Gitlin et al., 2001).

Working with the family. The FCC approach was not always used in OTHP outcome evaluation. Evaluating outcomes with the family aligns with FCC central belief that parents know their child best and should be involved in all clinical decision-making (Rosenbaum et al., 1998). Also, the need for occupational therapists to systematically collaborate with families at all stages of the OTHP process is supported in the literature to: build evidence about what works best and for whom; to improve health outcomes for families; and facilitate deep learning for student occupational therapists working with CWCP on placement, of the links between evidence and practice (King and Chiarello, 2014;-Nash and Mitchell, 2017). 


\section{Uptake and application of evidence-based interventions}

The uptake of evidence-based interventions, such as coaching, action observation therapy, CO-OP, Bimanual Training (BT), and m-CIMT/CIMT varied. This concurs with existing evidence of the gap between the use of high quality evidence, and what is actually offered to people with CP (Saleh et al., 2008; Rodger, Brown, and Brown, 2005.; McConnell et al., 2012). Literature supports the use of interventions such as parent-delivered action observation therapy, BT and CIMT/m-CIMT within OTHPs to improve upper limb function in CWCP (Kirkpatrick et al., 2016; Sakzweski et al., 2013). Similarly, coaching and CO-OP interventions for CWCP is supported with evidence (Novak et al., 2013). Furthermore, guidelines state that task-focused active-use therapies such as CIMT are followed by bimanual therapy in therapy programmes (NICE, 2012, p. 19). While it is recognised that "CIMT is not the panacea for children with unilateral CP", evidence supports its effectiveness if used "for the right children at the right time" (Hoare, 2015, p.13). However, mCIMT/CIMT can be time-intensive and expensive to use and optimal dosing is unknown (Novak et al., 2013). It is also acknowledged, that as with all interventions delivered within the home, parental time and commitment is required and engagement from both parents and therapists (Kirkpatrick et al., 2016).

The inconclusive response to the statement regarding confidence in designing OTHPs and statements made regarding OTHP professional development, concurs with research by Sakzweski et al (2013) that there is a need for training and skill development in using evidence-based OTHPs. Published OTHP nationally agreed OTHP protocols, detailed specification of intervention OTHP content, and continuing professional support for clinicians would help translate evidence into OTHP practice. 


\section{Measurement of child and family goals}

The scarcity in the uptake and use of measures to measure child and family goals, was incongruent with OTHP studies that support the use of these types of measures for giving parents and children a voice (Milton and Roe, 2017). This finding concurs with previously published research in paediatric rehabilitation that the routine use of standardised outcome measures remains low (Sakzewski, Ziviani and Boyd, 2016; McConnell, Johnston and Kerr, 2012; Hannah et al., 2007; Saleh et al., 2008; Unsworth, 2001). To align with the Department of Health's 'Equity and excellence: liberating the NHS' in 2010, COT policy (2015) and evidence-based CP literature (Novak et al., 2013), using measures such as the COPM, GAS and PEGS to measure goal attainment strengthen quality outcomes for CWCP. The COPM and GAS are well-validated processes that align with FCC and provide a robust, flexible structure of setting goals with families. Furthermore, the COPM has been found to be beneficial and effective for providing an occupational-focused lens, plus measuring activities and participation (Donnelly et al., 2017). In response to open-ended questions, occupational therapists identified the need for further professional development in goal-setting.

\section{Evaluation of OTHP outcomes}

The type of objective outcome measures used was limited, although successful OTHP evaluation is supported through the use of a range of outcome measures not just goalattainment (Novak, Cusick and Lannin, 2009; Milton and Roe, 2017). For example, despite the frequency of fine motor activities prescribed, fine motor assessments were rarely used to measure progress or change. The comprehensive use of measures to measure OTHP outcomes 
would also strengthen confidence in OTHP effectiveness. Research by Unsworth (2001) recommends that improved uptake and application of outcome measures requires greater availability of training for practitioners, the routine inclusion of training materials for students and support from managers.

The use of goal-measurement post-OTHP to evaluate outcomes was more than the $17 \%$ reported in the literature (Kolehmainen et al., 2012). To embed FCC into practice on-going measurement of goals and evaluation of outcomes with families need to be robust and occur routinely (Sakzewski et al, 2013). Outcome review needs to be agreed pre-OTHP. This is supported by Oien et al (2009) who identified that parents find it useful if goals are set for a given time frame, are concrete, observable, contextualised, written, and visible for everyone involved with the child.

\section{Implications}

Current occupational therapy practices with respect to OTHPs for CWCP include the predominant use of a FCC framework, varied uptake of evidence-based interventions and measures as well as a professional reasoning process grounded in theory to support the occupational well-being of families. The implications to ensure OTHP approaches, interventions and measures for CWCP are based on current evidence are shown in Table 1.

Table 1: Recommendations for enhancing quality OTHP outcomes. 


\section{Limitations}

The limitations of the present study include: firstly, restriction of sampling only to occupational therapy UK members; secondly, it was not possible to calculate a response rate as there is no data available on the total number of paediatric occupational therapists working in the UK. Thirdly, influence of social desirability bias on data collection as data presented in this study were occupational therapists' own reports of their practice. Fourthly to keep within the ten minute survey completion time information on respondent demographics was limited.

\section{Conclusion}

This is the first published survey to identify the current usage, content and professional reasoning process supporting OTHPs for CWCP which is relevant both at a national level for the development of OTHPs, and at an international level to support the world-wide drive to translate the best available evidence for CWCP into practice. Despite the world-wide emphasis and support for FCC, evidence-based practice and use of outcome measures in occupational therapy (Law et al., 2005; King and Chiarello, 2014), the profession appears to have some distance to go in implementing best practice routinely in OTHPs for CWCP. Every child with $\mathrm{CP}$ is different and every OTHP and each child's outcome will be unique. The parents' voice must be heard and made real: it is their right to have an OTHP consisting of the most effective interventions, framed by their own and child's goals and evaluated with valid measures. Published OTHP clinical guidelines for CWCP, detailed specification of intervention OTHP content and therapist support, will help translate evidence into OTHP practice. Further descriptive research is required to understand more fully the barriers and identify solutions to target context-specific OTHP barriers. 


\section{Key findings}

- An urgent need for routine application of standardised measurement tools, evidence-based interventions and family-centred approach is indicated.

- Therapists identified the need for further professional development in OTHPs

\section{What the study has added}

This study has identified relevant outcome measures, evidence and the use of family centred practice for supporting OTHPs for children with cerebral palsy and the gaps in UK clinical practice

\section{Acknowledgements}

We would like to acknowledge the occupational therapists who participated in this research for providing their valuable time and insight.

\section{Research Ethics}

Ethical approval was obtained from Coventry University Ethics Committee, reference number P49948 in 2017. All participants provided informed consent on the consent form within the online survey prior to completing the survey. 


\section{Declaration of conflicting interests}

The authors declared no potential conflicts of interest with respect to the research, authorship, and/or publication of this article.

\section{Funding}

The authors received no financial support for the research, authorship, and/or publication of this article.

\section{Contributorship}

Yvonne Milton conceived the study paper and design, researched the literature, applied for ethical approval, developed and promoted the survey, collected data and led on manuscript preparation. All authors contributed with data analysis, critically reviewed and edited the manuscript. All authors approved the final version of the manuscript.

\section{References}

Cameron D, Craig, T, Edwards B, et al. (2017) Cognitive orientation to daily occupational performance (CO-OP): A new approach for children with cerebral palsy. Physical and Occupational Therapy in Pediatrics 32(2): 183-198

Carnahan K, Arner M and Hagglund G (2007) Association between gross motor function (GMFCS) and manual ability (MACS) in children with cerebral palsy. A populationbased study of 359 children. BMC Musculoskeletal Disorders 8(1): 50-56.

College of Occupational Therapists (2015) Code of Ethics and Professional Conduct. London: College of Occupational Therapists. 
Department of Health and Social Care (2010) Equity and excellence: liberating the NHS. London: United Kingdom: Crown Copyright Stationary Office Limited.

Donnelly C, O’Neill C and Bauer M (2017) Canadian occupational performance measure in primary care: a profile of practice. American Journal of Occupational Therapy 71(6): $1-4$.

Gitlin LN, Corcoran MA, Winter L, et al. (2001) A randomized controlled trial of a home environmental intervention to enhance self-efficacy and reduce upset in family caregivers of persons with dementia. Gerontologist 41(1): 4-14.

Hanft B and Pilkington O (2000) Therapy in natural environments: the means or end goal for early intervention? Infants and Young Children 12(4): 1-13.

Health and Care Professions Council (2013) Standards of Proficiency Occupational Therapists. London

Hoare B (2015) Constraint therapy, the panacea for unilateral cerebral palsy? Developmental Medicine \& Child Neurology 57(1): 12-13.

IBM Corp. Released 2016. IBM SPSS Statistics for Windows Version 24.0, Armonk, NY: IBM Corp.

King G and Chiarello L. (2014) Family-centred care for children with cerebral palsy: conceptual and practical considerations to advance care and practice. Journal of Child Neurology, 29, 1046-1054.

Kiresuk TJ and Sherman RE (1968) Goal Attainment Scaling: a general method for evaluating comprehensive community mental health programs Community Mental Health Journal 4: 443-453.

Kirkpatrick E, Pearse J, James P, et al. (2016) Effect of parent-delivered action observation therapy on upper limb function in unilateral cerebral palsy: a randomized controlled trial. Developmental Medicine and Child Neurology 58(10): 1049-56 
Krumlinde-Sundolm L, Holmefur M, Kottorp A, et al. (2007) Assisting hand assessment: current evidence of validity, reliability and responsiveness of change. Developmental Medicine and Child Neurology 49(4): 259-264.

Kolehmainen N, MacLennan G, Ternent L, et al. (2012) Using shared goal setting to improve access and equity: a mixed methods study of the good goals intervention in children's occupational therapy. Implementation science 7(1): 76-86.

Law M, Baptiste S, Carswell A, et al. (2014) The Canadian Occupational Performance Measure, $5^{\text {th }}$ ed. Ottawa: CAOT Publications.

McConnell K, Johnston L and Kerr C (2012). Therapy management of the upper limb in children with cerebral palsy: A cross-sectional survey. Developmental Neurorehabilitation 15(5): 343-350.

Milton YM and Roe SA (2017) Occupational therapy home programmes for children with unilateral cerebral palsy using bimanual and modified constraint induced movement therapies: a critical review. British Journal of Occupational Therapy 80(6): 337-349.

Nash BH and Mitchell AW (2017) Longitudinal study of changes in occupational therapy students' perspectives on frames of reference. American Journal of Occupational Therapy 71(5): 1-7.

National Institute for Health and Clinical Excellence (2012) Spasticity in under 19s: management, Clinical Guideline 145. Available at: https://www.nice.org.uk/guidance/cg145 (accessed 15 March 2016).

Novak I and Cusick A (2006) Home programmes for children with cerebral palsy: where to start? Australian Journal of Occupational Therapy 53(4): 251-264.

Novak I, Cusick A and Lannin N (2009) Occupational therapy home programs for cerebral palsy: Double-Blind, Randomised, Controlled Trial. Pediatrics, 24, 606-614. 
Novak I (2011) Parent experience of implementing effective home programs.

Physical and Occupational Therapy in Pediatrics 31(2): 198-213.

Novak K, McIntyre S, Morgan C, et al. (2013) A systematic review of interventions for children with cerebral palsy: state of the evidence. Developmental Medicine and Child Neurology 55(10): 885-910.

Novak I and Berry J (2014) Home program intervention effectiveness evidence. Physical and Occupational Therapy in Pediatrics 34(4): 384-389.

Oien I, Fallang B and Ostensjo S (2010) Goals setting in paediatric rehabilitation: perceptions of parents and professionals. Child Care Health and Development 35(4): 558-565

Oskoui M, Coutinho F, Dykeman I, et al. (2013) An update on the prevalence of cerebral palsy: A systematic review and meta-analysis. Developmental Medicine and Child Neurology, 55(6): 509-519.

Pollock N and Missiuna C (2015) The Perceived Efficacy and Goal Setting System $2^{\text {nd }}$ Ed. Canada: CanChild Centre for Childhood Disability Research, McMaster University.

Proffitt R (2016) Home exercise programs for adults with neurological injuries:

A survey. The American Journal of Occupational Therapy 70(3): 1-8.

Rodger S and Ziviani J (2006) Occupational Therapy with Children Understanding Children's Occupations and Enabling Participation. Blackwell Publishing.

Rodger S, Brown BT and Brown A (2005) Profile of paediatric occupational therapy practice in Australia. Australian Occupational Therapy Journal 52(4): 311-325.

Rosenbaum P, King S, Law M, et al. (1998) Family-centred service: a conceptual framework and research review. Physical and Occupational Therapy in Pediatrics 18(1): 1-20.

Sakzewski L, Ziviani J and Boyd RN (2013) Delivering evidence-based upper limb rehabilitation for children with cerebral palsy: barriers and enablers identified by three pediatric teams. Physical and Occupational Therapy in Pediatrics 34(4): 368-383. 
Sakzewski L, Ziviani J and Boyd RN (2016) Translating evidence to increase quality and does of upper limb therapy for children with unilateral cerebral palsy: A pilot study. Physical and Occupational Therapy in Pediatrics 36(3): 305-329.

Saleh M, Korner-Bitensky N, Snider L, et al. (2008) Actual vs. best practices for young children with cerebral palsy: a survey of paediatric occupational therapists and physical therapists in Quebec, Canada. Developmental Neurorehabilitation 11(1): 6080.

Unsworth C (2001) Measuring the outcome of occupational therapy: tools and resources. Australian Occupational Therapy Journal 47(4): 147-158. 
Figure 1. Approaches, theories, conceptual models of practice and frameworks used by respondents

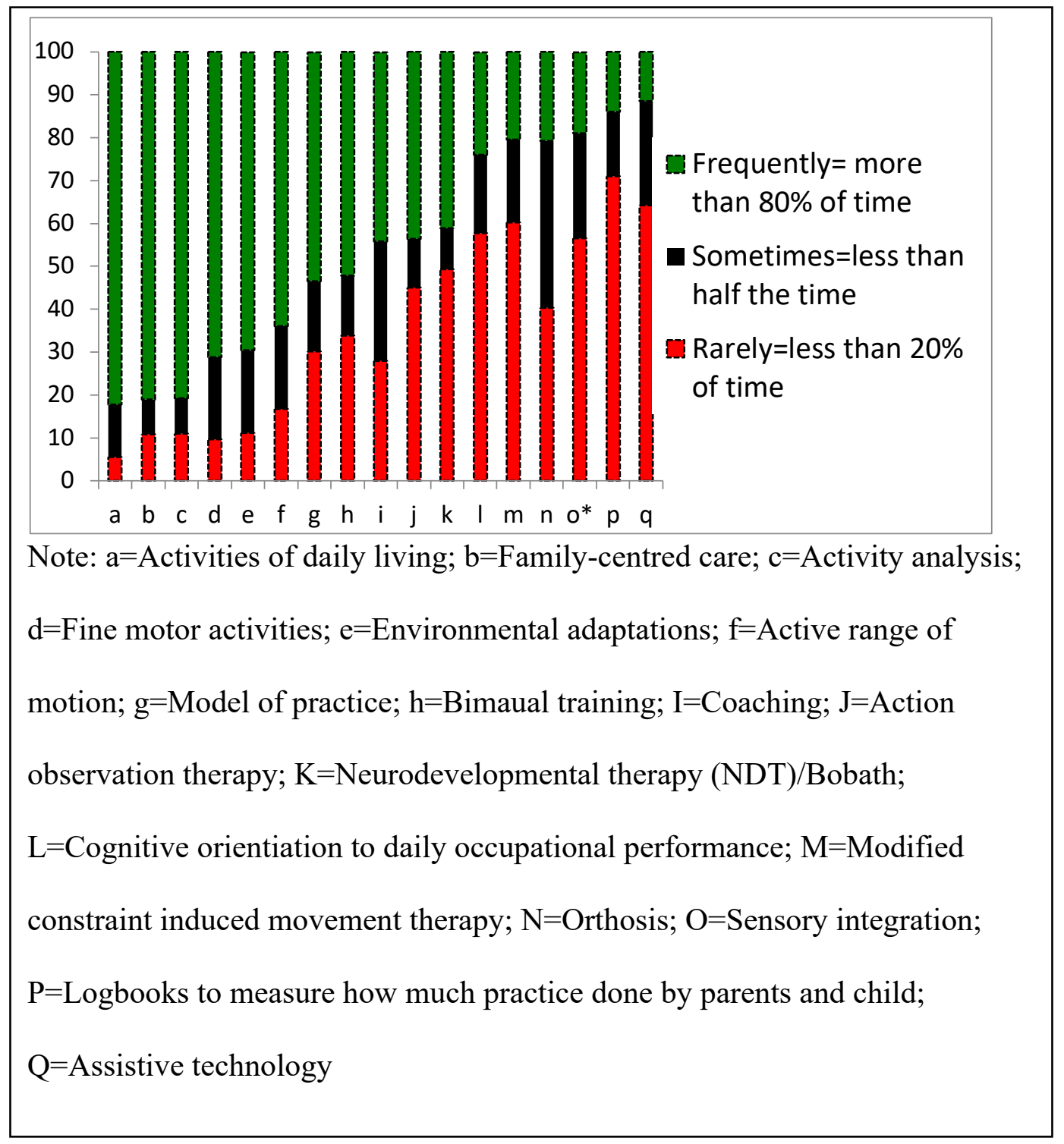


Figure 2. Type and use of Measures used by respondents

Note: $\mathrm{a}=$ Goals are occupation focused; $\mathrm{b}=$ Goals set in collaboration with
parents; c=Environmental assessments; $\mathrm{d}=$ Goals set in collaboration with child;
E=outcome evaluation with family; $\mathrm{f}=$ Goals measured objectively prior to
Starting OTHP; $\mathrm{g}=$ Goals measured objectively after carrying out the OTHP; $\mathrm{h}=$
Goal Attainment Scaling; $\mathrm{i}=$ Participation measure; $\mathrm{j}=$ Gross Motor Function
Classification Scale; $\mathrm{k}=$ Bimanual performance


Table 1: Recommendations for enhancing quality OTHP outcomes.

\begin{tabular}{|c|c|}
\hline What & How \\
\hline Interventions & $\begin{array}{l}\text { - Clinicians to advocate for training, guidance } \\
\text { through supervision and practice to develop goal- } \\
\text { setting skills and use to do effective evidence- } \\
\text { based OTHPs } \\
\text { - Provide regular parental support and coaching to } \\
\text { identify improvements in the child's occupational } \\
\text { performance whilst continuing to provide the } \\
\text { 'just right challenge' }\end{array}$ \\
\hline Measures & $\begin{array}{l}\text { - Adopt an explicit goal-setting process } \\
\text { - Use occupationally-focused goals } \\
\text { - Make OTHP goals clear, contextualised and } \\
\text { written with a review date } \\
\text { - Review OTHP hand-outs to ensure goals are } \\
\text { included } \\
\text { - Use standardised assessments pre/post OTHP } \\
\text { systematically } \\
\text { - The GMFCS and MACS are valuable tools to } \\
\text { describe motor function }\end{array}$ \\
\hline Professional Reasoning & $\begin{array}{l}\text { - Talk about professional reasoning in team } \\
\text { meetings as this helps to incorporate } \\
\text { occupational therapy research evidence into } \\
\text { practice }\end{array}$ \\
\hline
\end{tabular}




\section{Appendix: Home Program Survey Questionnaire}

Dear Occupational Therapy Colleague,

I am leading a study to determine current practices of Occupational Therapists working with children and young people with cerebral palsy. Specifically, I am interested in understanding the nature of home programmes. This survey is designed to gather information on current occupational therapy practices in prescribing, carrying out, and managing a home programme for a child or young person with cerebral palsy. To determine the overall response rate and frequency of home programme practice, even if you do not use home programmes for children and young people with cerebral palsy, I would be grateful if you could indicate this by clicking 'No' to question 1 below; you will then be directed to a part of the survey where you are asked to complete one further quick question about this. However, if you do treat children and young people with cerebral palsy using home programmes, please consider filling out this survey which takes 8 minutes to complete. This survey is completely anonymous and no identifying information will be collected. To complete the survey, simply click on 'Yes' to the question 1 below which will take you to the consent form. Thank you for your consideration. I look forward to receiving your response. Sincerely,

1. Do you prescribe home programmes for children and young people with cerebral palsy?

Yes - Continue to consent page.

No- Go to final page (link to page) 


\section{Consent Form for the Online Survey}

Project title: Home Programmes for Children and Young People with Cerebral Palsy study

\section{Researcher's name -}

I confirm that I have read the information sheet attached to the email inviting me to take part in the study and understand the purpose of the research project and my involvement in it. I understand and agree to take part.

I understand that whilst information gained during the study may be published, I will not be identified and my personal results will remain confidential.

I understand that data will be stored in the strictest of confidence and will only be reported in an anonymised form. Electronic copies of the data will be stored on the secure server in a location that is password protected and only accessible to the researcher.

I understand that I may contact the researcher if I require further information about the research, and that I may contact the Research Ethics Co-ordinator, if I wish to make a complaint relating to my involvement in the research.

Yes I agree to carry out the survey (link to survey:

No I don't agree (link to "Thank you for taking the time to consider this study"). 
BACKGROUND: These next few questions are about you as an Occupational Therapist

2. How many years have you been practised as an Occupational Therapist?

○ $0-5$ years

○ 6-10 years

○ 11-15 years

- 15-20 years

- Over 20 years

3. Who is your employer? (Demographic data)
Self employed
NHS
Charity
Community based
Education
Voluntary agency
$\square$ Social services
$\square$ Other

HOME PROGRAMMES: The next questions are specifically about home programmes for children with cerebral palsy

4. Which classifications of cerebral palsy do you use home programmes for? (select all that apply)
$\bigcirc$ Children with quadriplegia
$\bigcirc$ Children with diplegia
C Children with hemiplegia
Other : If you selected other please specify: 
5. Choose the option for each statement that best fits your opinion. There are no right or wrong answers.

\begin{tabular}{|c|c|c|c|}
\hline Home Programme Statements & \begin{tabular}{|l}
$\begin{array}{l}\text { Strongly } \\
\text { Agree }\end{array}$ \\
\end{tabular} & Neutral Disagree & $\begin{array}{l}\text { Strongly } \\
\text { Disagree }\end{array}$ \\
\hline $\begin{array}{l}\text { I prescribe home programmes for all } \\
\text { the children I see with cerebral palsy, } \\
\text { regardless of classification }\end{array}$ & & $\frown$ & \\
\hline $\begin{array}{l}\text { I prescribe home programmes because } \\
\text { consistency of therapeutic approach is } \\
\text { important }\end{array}$ & $\bigcirc$ & ) & ) \\
\hline $\begin{array}{l}\text { I usually prescribe a home programme } \\
\text { because it helps children meet goals } \\
\text { that cannot be met with the limited } \\
\text { amount of one-to-one therapy allotted. }\end{array}$ & & & ) \\
\hline $\begin{array}{l}\text { Home programmes reinforce carryover } \\
\text { of therapy activities into the child's } \\
\text { environment }\end{array}$ & ) & O & D \\
\hline $\begin{array}{l}\text { Home programmes allow for greater } \\
\text { participation in the child's natural } \\
\text { environment }\end{array}$ & ) & & \\
\hline
\end{tabular}


6. Do the following interventions/theory/methods influence your home programmes for children and/or young people with cerebral palsy?

\begin{tabular}{|c|c|c|c|c|c|}
\hline $\begin{array}{l}\text { Intervention/Theory } \\
\text { Method/ Assessment }\end{array}$ & Never & $\begin{array}{l}\text { Rarely } \\
\text { (about } \\
20 \% \text { of the } \\
\text { time) }\end{array}$ & $\begin{array}{l}\text { Sometimes } \\
\text { (less than } \\
\text { half the } \\
\text { time) }\end{array}$ & $\begin{array}{l}\text { Often } \\
\text { (more than half } \\
\text { of the time) }\end{array}$ & $\begin{array}{l}\text { Usually } \\
\text { (about } 80 \% \\
\text { of the time) }\end{array}$ \\
\hline $\begin{array}{l}\text { An occupational therapy } \\
\text { model of practice }\end{array}$ & & & & & \\
\hline Action observation therapy & & & & & \\
\hline Active range of motion & & & & & \\
\hline $\begin{array}{l}\text { Bimanual performance } \\
\text { outcome measure/s }\end{array}$ & & & & & \\
\hline Bimanual training & & & & & \\
\hline Bobath therapy & & & & & \\
\hline Coaching & & & & & \\
\hline $\begin{array}{l}\text { Cognitive orientation to } \\
\text { daily occupational } \\
\text { performance (CO-OP) }\end{array}$ & & & & & \\
\hline $\begin{array}{l}\text { Constraint induced } \\
\text { movement therapy }\end{array}$ & & & & & \\
\hline Electronic games/apps & & & & & \\
\hline Environmental adaptation & & & & & \\
\hline $\begin{array}{l}\text { Environmental } \\
\text { assessments }\end{array}$ & & & & & \\
\hline
\end{tabular}




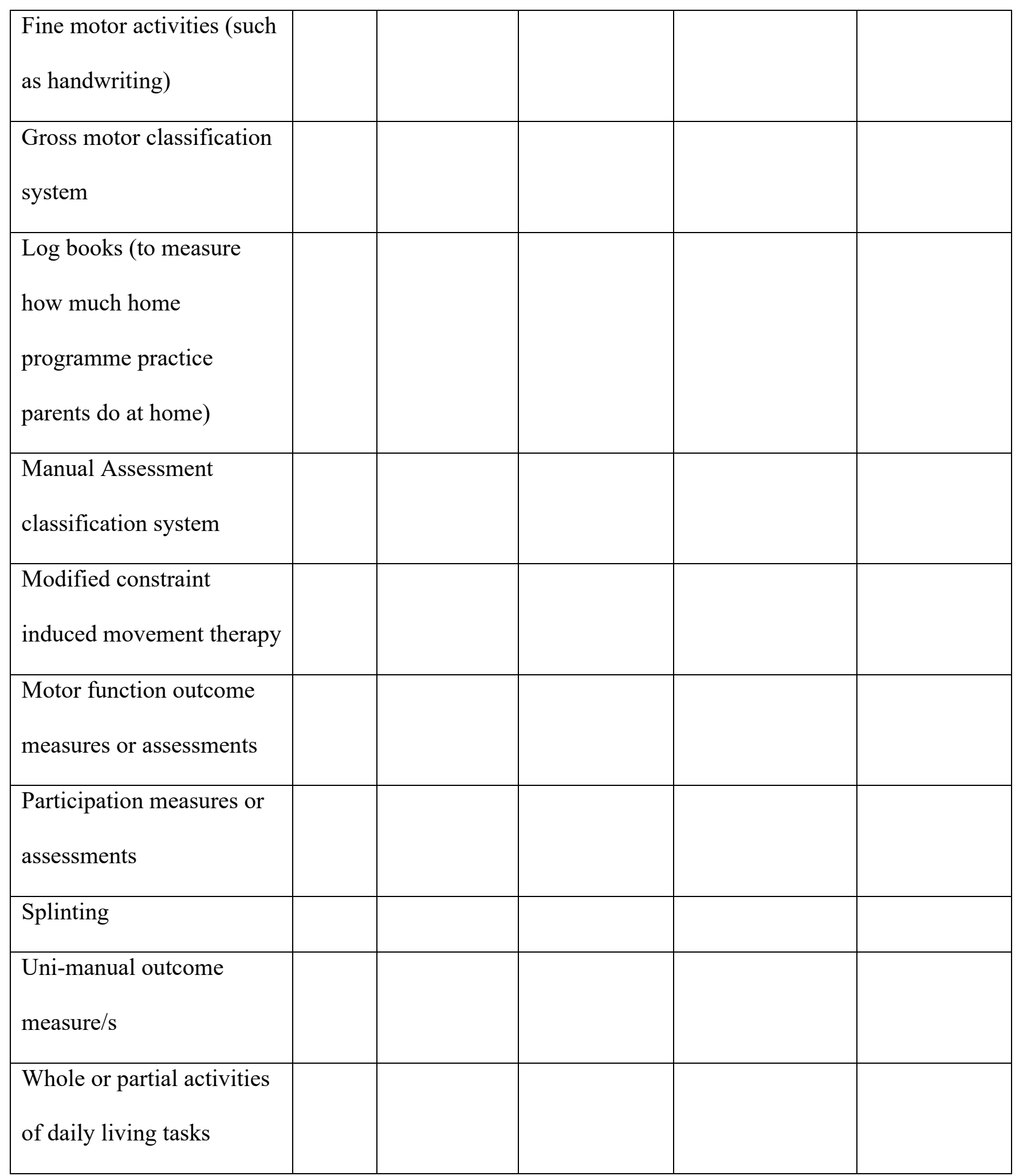

If you use anything else, or have any comments to make regarding the interventions, theory and methods shown in the table above, or the type (s) of classification of children with 
cerebral palsy you use them with, or the type of splint you use, please do so here:

7.What do you think about your home programmes ? Please rate how strongly you agree or disagree with the following statements.

\begin{tabular}{|c|c|c|c|c|c|}
\hline $\begin{array}{l}\text { Home Programme Design \& } \\
\text { Support Provided }\end{array}$ & $\begin{array}{l}\text { Strongly } \\
\text { agree }\end{array}$ & Agree & $\begin{array}{l}\text { Neither } \\
\text { agree or } \\
\text { disagree }\end{array}$ & Disagree & $\begin{array}{l}\text { Strongly } \\
\text { disagree }\end{array}$ \\
\hline They are effective & & & & & \\
\hline $\begin{array}{l}\text { I am confident designing and } \\
\text { using them }\end{array}$ & & & & & \\
\hline $\begin{array}{l}\text { They need to be designed in the } \\
\text { home environment }\end{array}$ & & & & & \\
\hline $\begin{array}{l}\text { They can be designed in the } \\
\text { home or school environment }\end{array}$ & & & & & \\
\hline $\begin{array}{l}\text { I am satisfied with the amount } \\
\text { of support I am able to provide } \\
\text { to parents carrying out a home } \\
\text { programme }\end{array}$ & & & & & \\
\hline $\begin{array}{l}\text { I am satisfied with how often I } \\
\text { use home programmes }\end{array}$ & & & & & \\
\hline $\begin{array}{l}\text { They need to be written with } \\
\text { photographs of the child doing } \\
\text { the activities. }\end{array}$ & & & & & \\
\hline
\end{tabular}




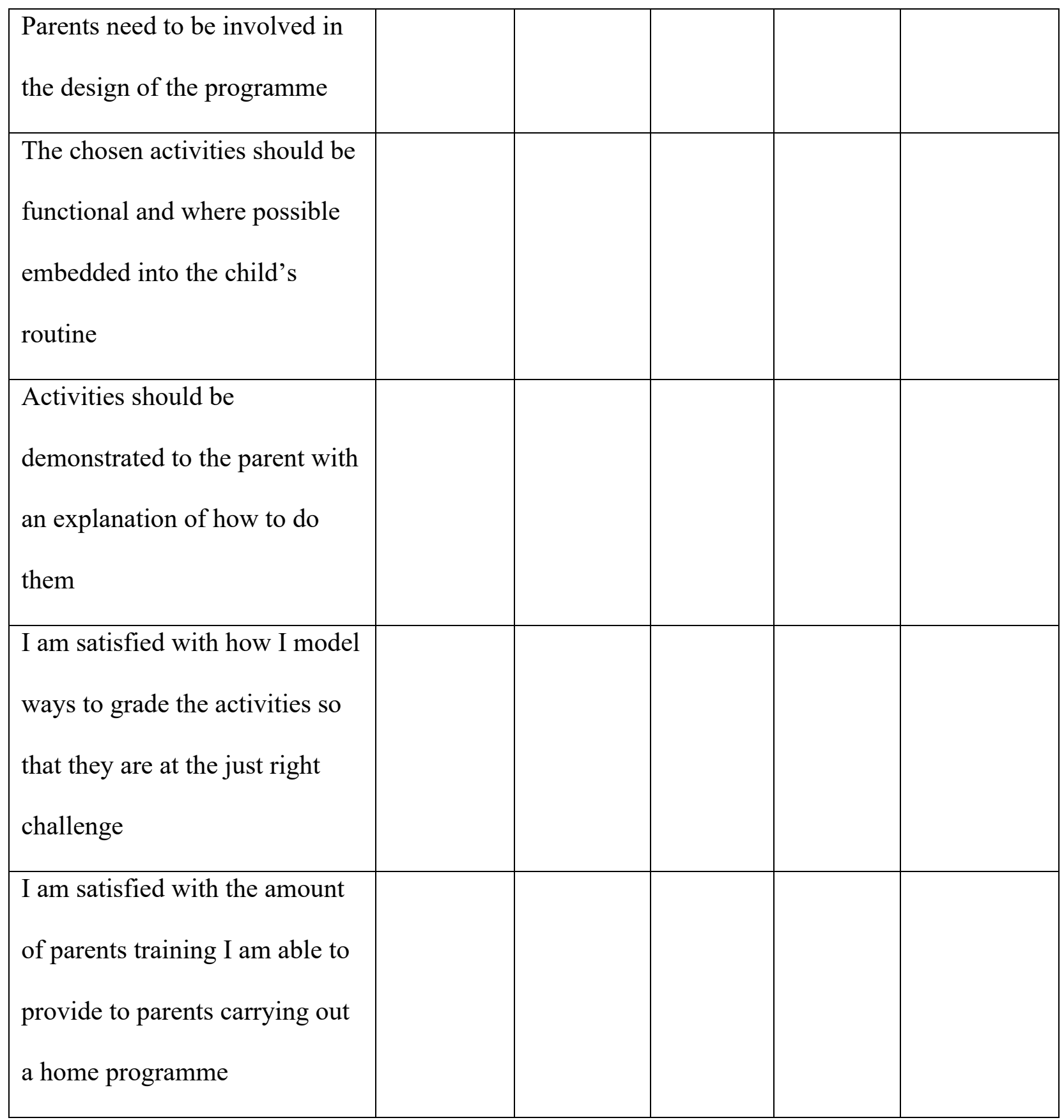

If you would like to make any other comments, please do so here: 
8. What is your experience of goal setting when using home programmes?

\begin{tabular}{|c|c|c|c|c|c|}
\hline $\begin{array}{l}\text { Method of Goal } \\
\text { Measurement }\end{array}$ & $\begin{array}{l}\text { Usually } \\
\text { (about } \\
80 \% \text { of } \\
\text { the } \\
\text { time) }\end{array}$ & $\begin{array}{l}\text { Often } \\
\text { (more than } \\
\text { half of the } \\
\text { time) }\end{array}$ & $\begin{array}{l}\text { Sometimes } \\
\text { (less than } \\
\text { half the } \\
\text { time) }\end{array}$ & $\begin{array}{l}\text { Rarely } \\
\text { (about } \\
20 \% \text { of } \\
\text { the time) }\end{array}$ & Never \\
\hline $\begin{array}{l}\text { The Canadian Occupational } \\
\text { Performance Measure is used }\end{array}$ & & & & & \\
\hline $\begin{array}{l}\text { Goals are set collaboratively } \\
\text { with the parents }\end{array}$ & & & & & \\
\hline $\begin{array}{l}\text { Goals are set collaboratively } \\
\text { with the child }\end{array}$ & & & & & \\
\hline $\begin{array}{l}\text { Goal Attainment Scaling } \\
\text { (GAS) is used }\end{array}$ & & & & & \\
\hline $\begin{array}{l}\text { The Perceived Efficacy of } \\
\text { Goal Setting Measure is used }\end{array}$ & & & & & \\
\hline $\begin{array}{l}\text { Goals are written separately } \\
\text { from the family }\end{array}$ & & & & & \\
\hline
\end{tabular}




\begin{tabular}{|l|l|l|l|l|l|}
\hline Goals are measured & & & & & \\
objectively prior to starting & & & & & \\
the programme & & & & & \\
specified time after carrying \\
out the programme
\end{tabular}

If you have any comments to make about your experience of using goals with home programmes, or use any other goal setting measure (s), please describe here:

\section{Barriers and enablers}

9. How much time, on average, do you recommend that a home programme is carried out? 
10. When you do you advise parents to carry out a home programme?

11.Are there any barriers that have an impact on your use of home programmes?

Yes

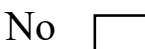

11 a. If you answered 'yes' please select the relevant barriers:

\begin{tabular}{|l|l|l|}
\hline & Yes & No \\
\hline Time & & \\
\hline Skills & & \\
\hline Knowledge of specific & & \\
\hline Training & & \\
\hline Support & & \\
\hline Other & & \\
\hline
\end{tabular}

If you selected 'other' please comment here:

12) Are there any factors that enable you to use home programmes? If so please comment here:

13) Please make any suggestion for the type and content of professional development/educational solutions you think would improve the design and use of your home programmes for children and young people with cerebral palsy here

14. What do you feel is beneficial about prescribing home programmes for children with cerebral palsy? 
15. What guides you professional/clinical reasoning when deciding the content for a home programme for children with cerebral palsy?

\section{ONLY ANSWER QUESTION 16 IF YOU SELECTED 'NO’ TO QUESTION 1:}

16. Please indicate any reason (s) below for why you may not be using home programmes for children with cerebral palsy. Your input would be greatly appreciated. (Please describe)

I work in an academic setting

I do not work regularly with children with cerebral palsy to use home programmes

Clients are unable to participate in a home programme because of the treatment setting

Home programmes are not the main focus of intervention

There are issues with client or caregiver compliance and follow through

I'm retired

Time constraints

$\square$ Support

$\square$ Knowledge of specific methods

$\square$ Other

If you selected 'other' please specify, your input is greatly appreciated. 
